\title{
Recurrent ischemia induced by unnoticed stent loss in the left main coronary artery
}

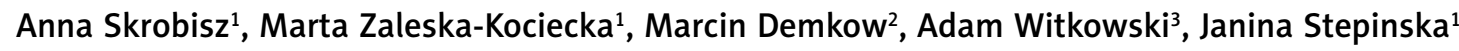 \\ ${ }^{1}$ Department of Intensive Cardiac Therapy, Institute of Cardiology, Warsaw, Poland \\ ${ }^{2}$ Department of Coronary and Structural Heart Diseases, Institute of Cardiology, Warsaw, Poland \\ ${ }^{3}$ Department of Interventional Cardiology and Angiology, Institute of Cardiology, Warsaw, Poland
}

Adv Interv Cardiol 2018; 14, 1 (51): 105-106 DOI: https://doi.org/10.5114/aic.2018.74365

One of the rare complications in percutaneous coronary interventions $(\mathrm{PCI})$ is failure of stent deployment. In this case, the authors address the difficulties of proper diagnosis in a patient with recurrent ischemia caused by failure of stent deployment.

A 92-year-old, obese female patient with a history of kidney failure was admitted with non-ST-elevation myocardial infarction (NSTEMI). The initial ECG showed ST-segment depression in leads $\mathrm{VVL}$ and V4-V6. Troponin I (Tnl) was $0.054 \mathrm{ng} / \mathrm{ml}$ (reference range $<0.013 \mathrm{ng} / \mathrm{ml}$ ). Coronary angiography revealed: $90 \%$ stenosis of the proximal left anterior descending (LAD), chronic occlusion of the right coronary artery (RCA) and 50\% stenosis of the highly calcified left main coronary artery (LMCA), which was estimated to be borderline (Figure $1 \mathrm{~A}$ ). Primary PCI of the LAD, which seemed to be the culprit lesion, was performed and three drug-eluting stents (DES) (BioMatrix $2.5 \mathrm{~mm} / 18 \mathrm{~mm}, 2.5 \mathrm{~mm} / 24 \mathrm{~mm}$ and $2.5 \mathrm{~mm} / 14 \mathrm{~mm}$ ) were implanted into the proximal and mid LAD with an excellent final angiographic result (Figure $1 \mathrm{~B}$ ). Chest pain resolved after the procedure but reappeared only $3 \mathrm{~h}$ later with ischemic changes in the ECG as previously. Control angiography confirmed undisturbed blood flow through the previously implanted stents (Figure $1 \mathrm{C}$ ). On the $6^{\text {th }}$ day of hospitalization the patient reported acute chest pain with concomitant significant ST segment depression in the precordial leads. Second control coronary angiography showed an unexpanded stent located in the LMCA (Figure 1 D) which caused 90\% LMCA stenosis and protruded into the aorta. The stent was removed with the snare loop (Figure $1 \mathrm{E}$ ). Left main coronary artery stenosis was reassessed as a significant lesion. After balloon dilatation, a new DES (Promus $3.5 \mathrm{~mm} / 12 \mathrm{~mm}$ ) was positioned in the LMCA (Figure $1 \mathrm{~F}$ ), resulting in complete resolution of angina.

Reported incidence of failure of stent deployment varies, ranging from $0.3 \%$ to $8.3 \%$ [1]. Several factors are associated with stent loss, including arterial calcification, tortuosity of the vessel, stent delivery through another stent and direct stenting [2]. A deep intubation technique was used at the first intervention. According to its characteristics, the platform used in the BioMatrix family of stents allows successful stent delivery even in a group of highly torturous and calcified vessels. However, the authors presume that a stent tine caught on the guide tip, leading to the stent being stripped from the balloon. Failure of stent deployment is a potentially life-threatening condition which can cause complications such as acute coronary syndrome, the need for coronary artery bypass graft surgery, and noncoronary sequelae after stent embolization [3]. Based on this case, patients with massive calcifications should undergo more stringent angiographic evaluations including intravascular ultrasound (IVUS), which could have resulted in earlier diagnosis.

\section{Conflict of interest}

The authors declare no conflict of interest.

\section{Corresponding author:}

Anna Skrobisz, Department of Intensive Cardiac Therapy, Institute of Cardiology, 42 Alpejska St, 04-628 Warsaw, Poland, phone: +48 2234343 14, e-mail: askrobisz@ikard.pl

Received: 18.10.2017, accepted: 31.01.2018. 

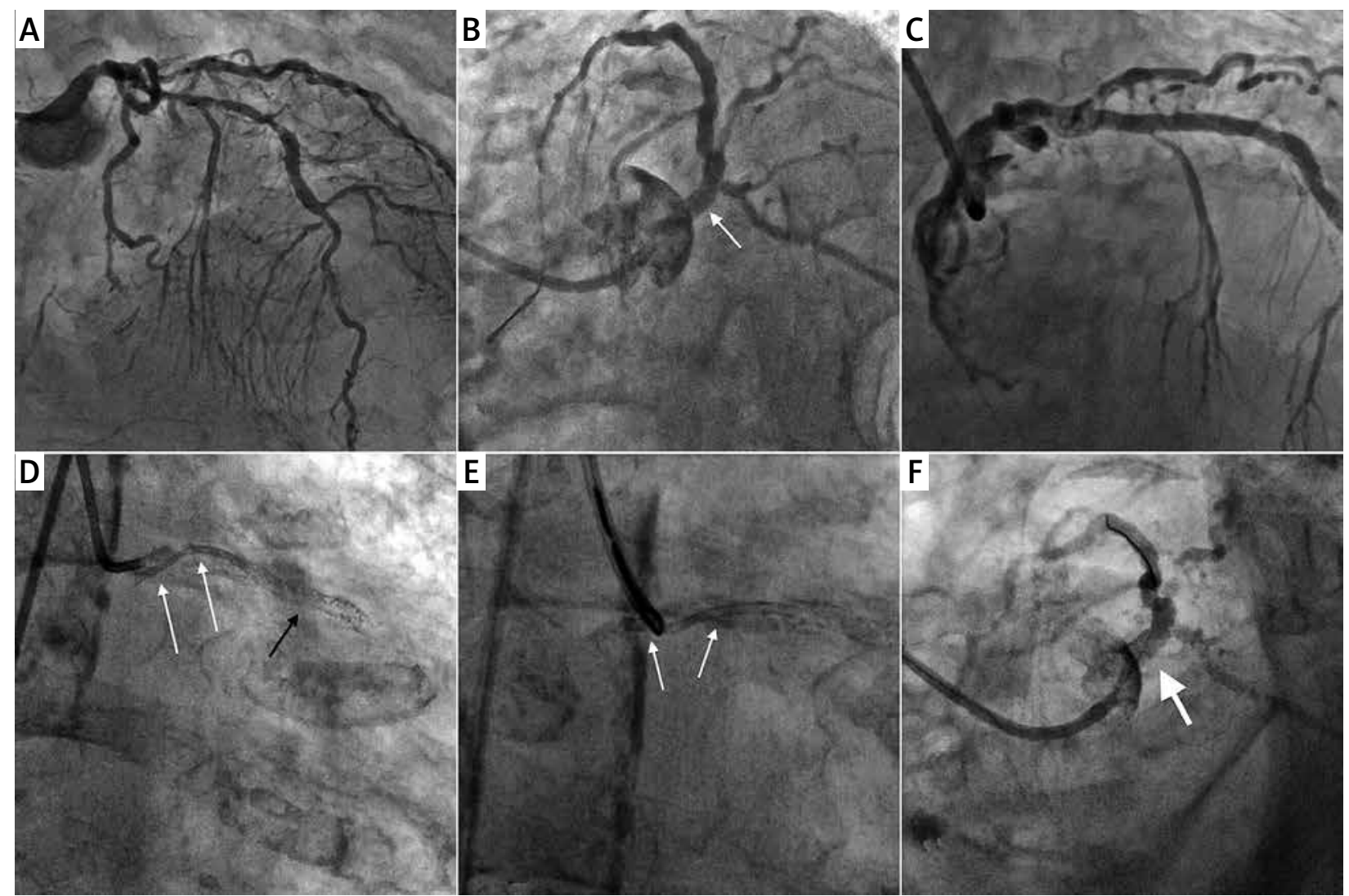

Figure 1. A - Coronary angiography of the left coronary artery showed massive calcification (CRA 26, RAO 6), B - final angiographic result (CAU 30, LAO 58), C - the first control (CRA 31, RAO 31), D - the second control showing the dislodged stent (white arrows) in the LMCA and the previously implemented stents (black arrow) (CRA 4, RAO 3), E - removing the stent (white arrows) with the snare loop (CAU 4, RAO 9), F - result of LMCA stenting (CAU 34, LAO 50)

\section{References}

1. Brilakis ES, Best PJ, Elesber AA, et al. Incidence, retrieval methods, and outcomes of stent loss during percutaneous coronary intervention: a large single-center experience. Catheter Cardiovasc Interv 2005; 66: 333-40.

2. Bolte J, Neumann U, Pfafferott C, et al. Incidence, management, and outcome of stent loss during intracoronary stenting. Am J Cardiol 2001; 88: 565-7.

3. Cantor WJ, Lazzam C, Cohen EA, et al. Failed coronary stent deployment. Am Heart J 1998; 136: 1088-95. 